\title{
Why Does the Press Still Matter? Explaining the Conditional Effects of Online Mobilization of Protest on Newspaper Market Structures in Asia
}

\author{
Shin Haeng Lee
}

In this study, it is argued that Internet-enabled opportunities for mobilization of elite-challenging politics are constrained by media systems in East and Southeast Asia. Particularly, Asian media systems are assumed to produce institutional constraints on digitally-mediated contexts of protest in that the wide reach of traditional news outlets increases the cost of access to alternative information sources. Multi-level modeling is thus used to test whether the impact of Internet use on unconventional political participation at the individual level is moderated by the presence of a mass-circulation print media at the countrywide level. The data came from the World Press Trends for media-system variables and the Asian Barometer Survey for the individual-level variables. It was found that, because Asian countries have a larger circulation of newspapers, unconventional political participation is predicted by Internet use to a lesser extent, but the impact of political interest was shown to increase. The findings suggest that, when media systems are structured by the development of a mass-circulation press, the mobilization capacity of digital networks is constrained by high information costs imposed by institutions on civil-society voices. Even if Internet use reduces the costs of grassroots organizing, its capacity to generate such organizing is contingent on users' political interest to overcome the barriers to alternative information sources. Discussion is undertaken to address the political implications of Asian media systems.

Key Words: Asian media systems, newspaper-market structure, online mobilization, unconventional political participation, multi-level modeling

*Shin Haeng Lee (shinlee@sejong.ac.kr) is an assistant professor in Sejong University’s Division of International Studies. His research examines the socio-political implications of digital media and big data using quantitative and computational social scientific methods. He earned his doctorate in communication along with a concentration in social science statistics at the University of Washington. Recently, he has had single-authored articles published in Journal of Information Technology and Politics, First Monday, and The Journal of Asiatic Studies. 
$\mathrm{T}$ he Hong Kong Umbrella movement and Taiwanese Sunflower movement in 2014, as well as the recent candlelight revolution in South Korea, are cases that show the potential of such digital media as the Internet and mobile phones to promote large-scale mobilizations of protest. Along with the widespread adoption of digitally-enabled social networking, especially in East Asia, protesters have been provided with a new channel of connecting and coordinating with the public (Ayres 1999; Bennett and Segerberg 2013; Castells 2012). The expansion of digital networks provides new mobilizing structures: civil society and activist groups are given a new means of communication for collectively organizing protest.

Certainly, even though people are afforded such opportunities to connect and coordinate, the technology does not necessarily cause grassroots mobilization across social contexts (Deibert et al. 2012; Morozov 2011; Pearce and Kendzior 2012). In Asia, the growth and entrenchment of online civil society corresponds neither to the prevalence of Internet use nor to the presence of democratic institutions for citizen participation (Abbott 2012; George 2006). Although people can be mobilized for a social or political cause, their participation does not take place in isolation from their surroundings, especially the socioeconomic, political, cultural, and media environments in which they are embedded (Van Laer 2010). Consideration of such contextual factors raises a question about the generalizability of the political impact of technology diffusion in Asia. Under what social conditions does Internet use enhance or hinder unconventional political participation?

This study argues that Internet use enables citizen mobilization differently across Asian countries with different media-system conditions. Previous studies found that media systems affect civic and political culture (Hallin and Mancini 2004; Norris 2000). Some research has also found that people have different patterns of civic learning and political involvement according to the ways in which media systems shape the cost structures of information acquisition (Aalberg and Curran 2012; Esser et al. 2012). This view maintains that political participation is affected by the mechanism through which people have lowcost opportunities to gain necessary information for being motivated (Curran et al. 2009; Shehata and Strömbäck 2011). Moreover, McAdam, Tarrow, and Tilly (2009) argue that mobilization of contentious politics is constrained by the mechanisms through which a person's ability and motivation matter in his or her learning about, evaluation of, and engagement in unconventional political activities. However, the literature has devoted less attention to comparative analysis of media systems that have an impact on opportunity structures for protest mobilization. More importantly, in some Southeast Asian countries, 
media systems reinforce an institutional framework for public discourses in which elite-challenging voices are marginalized (George 2006). Thus, the analysis of Asian media systems adds to a better understanding of political mobilization in this new information environment.

In this study, media systems are conceptualized as a structural condition that affects communication opportunities for non-institutional alternative media, and collective organizing by civil-society groups. That is to say, media systems constitute traditional institutions that shape the costs for the masses to be informed about, and mobilized for, elite-challenging politics. Therefore, digitally-enabled activists have different cost structures for mass mobilization according to how media markets are organized for public communications, as well as any presence of direct government controls of information. In particular, Asian media systems have such effects on mobilization of unconventional political participation because their newspaper market structures affect the costs of political information in relation not only to institutional barriers to Internetmediated dissident voices but also to the increasing primacy given to personal motives for engaging in politics.

By the newspaper market structure here we refer to an essential element of media systems: that traditional institutions are entrenched in the mediated formation of publics. It is a useful measure of media systems in the sense that the development of newspaper market structures, i.e. the wider reach of a masscirculation press, is a proxy for the degree to which political information is easily accessible by institutions so that contentious politics, enabled by Internet use, depends more on the ability and motivation of citizens than on increasing communication opportunities, alone. Even if the Internet has the potential to change the cost structures of unconventional political participation, its impact will therefore be contingent on the pre-existing circumstances for people to be informed about contentious politics and mobilized for unconventional action. In the following section, how Internet use has an impact on unconventional political participation and why a cross-national variation in Asian media systems are important for understanding opportunity structures for mobilization will be discussed. Subsequently, this research focuses on newspaper-market structures to investigate the contextual influence of media systems on political action.

\section{WHY IS INTERNET USE IMPORTANT?}

Since the classic studies of Verba, Nie and Kim (1978), political participation has been understood as being manifested in various forms and means to different 
extents. Putting aside its multidimensionality, political participation increasingly has manifested in unconventional forms in many countries (Inglehart and Welzel 2009). Barnes and Kaase (1979) argue that unconventional modes of political participation are realized through protest activities to challenge elitedriven politics through large-scale collective efforts needed to achieve a political goal. Signing petitions, attending demonstrations, or joining boycotts are the examples of such unconventional political acts. In doing so, unconventional political participation allows people to express their opinions about the decisionmaking process directly, rather than being mediated or orchestrated by a political elite, either directly or indirectly. This is crucial to the consolidation of democracy (Dahl 1998; Delli Carpini 2004).

Unconventional political participation usually involves collective action; however, it takes place in a distinctive way from its conventional counterpart. Admittedly, conventional political participation, such as attending a campaign meeting, working on behalf of a candidate, voting, writing one's congressman, has been explained by the ability and motivation of individuals to participate; there are proven correlations between education levels and level of political interest (Verba, Schlozman and Brady 1995). On the contrary, unconventional political participation relies on networked agencies of mobilization. Distinct from traditional, hierarchical structures of political participation, these networked agencies are characterized by fluid identities and relatively horizontal organization structures (Norris 2002). Therefore, it is not surprising that the diffusion of Internet use is increasingly seen as promising opportunities for grassroots civil-society organizations to mobilize unconventional political participation among the mass citizenry.

Indeed, Internet use has had political impact in the diverse contexts of various political movements, as the technology is believed to provide bottomup channels of communication and organization (Ayres 1999). The political capacity of Internet technology is also attributed to its broader effects on social capital (Shirky 2011). As long as it empowers those civil-society actors used to being deprived of resources for bridging social networks and coordinating collective action, Internet-mediated mobilization has necessitated neither the existence of a strong middle-class nor the entrenchment of those democratic institutions that used to be necessary for mass mobilization (Howard 2010). Howard (2015) further argues that Internet use is considered a primary means of communication for overcoming the cost-benefit problem of social mobilization. Indeed, a strong body of scholarship has substantiated that the lower the information costs for civic-minded citizens, the greater the incentives for them to engage in political action (Bimber 2003; Prior 2007). More importantly, 
because Internet users experience reduced costs for learning about contentious issues and being involved in various modes of action, they can more easily grasp how their participation satisfies their own personal and political goals (Bennett and Segerberg 2013).

Of course, there is much evidence showing personal motivation to have a much greater impact than Internet use alone. From this perspective, political interest is the key to translating communication opportunities into political action (Bimber 2003; Xenos and Moy 2007). This reinforcement thesis suggests that the political capacity of technology mirrors a pre-existing inequality in any intra-personal resource for incentivizing individuals to act on a political cause by expressing their political interests. Furthermore, at the national level, not every civil society benefits from Internet usage in terms of mass mobilization for a political cause. Particularly, East and Southeast Asian countries are characterized by diversity with respect to their levels of the entrenchment of civil-society organizations to organize and mobilize for political action. The classification of Asian countries according to their political, socio-economic, and cultural conditions is important to understanding cross-national variations not only in political participation, but also in the mobilizing role of Internet usage. Along with existing socio-economic inequality, Asian countries vary widely in the accessibility and the affordability of Internet usage (DiMaggio et al. 2001). The 'digital divide' is further deepening between and within countries because of different government controls over content and service providers (Morozov 2011). Government controls apply to access and the flow of information and its content, and state censorship has gained legitimacy through its ostensible opposition to cultural imperialism (Deibert et al. 2012).

\section{WHY ARE MEDIA SYSTEMS IMPORTANT?}

Unconventional political participation varies not only at the individual level but also at the societal level insofar as elite-challenging forms of collective action involve different opportunities and risks in a systematic way among the participants and their surroundings (Stockemer 2014). In particular, the mobilizing capacity of Internet use should be related to cross-country variation in those political institutions that shape the costs of communications for collective action. Some East and Southeast Asian countries maintain unfavorable opportunity structures for the mobilization for unconventional political participation due to illiberal institutions and restrictive governments, as well as dealing with socio-economic inequality in access to communication technologies 
(Pearce and Kendzior 2012). Whether media systems have any effects on opportunity structures has yet to be properly explored in the literature.

Certainly, regime types and media systems are related in important ways. Media development mutually re-enforces democratic development and civil liberalization (Mughan and Gunther 2000). Yet in East and Southeast Asia, types of governance and the organization of media institutions are quite diverse, so that one of these aspects alone does not capture the full range of features of each country's polity. Previous consideration of governing institutions is therefore insufficient to explain fully why some democracies recently have been troubled by the collective organizing of digitally-enabled youth for contentious political action, while some autocrats seem exempt from the mobilizing capacity of Internet use (Castells 2012; Morozov 2011).

At the societal level, political participation is contingent on the cost and opportunity structures of communication (Shehata and Strömbäck 2011). The reduce costs of political information lessen the gap in public involvement resulting from inequality in the ability and motivation of people to be informed about, and involved in, public life. Such individual-level inequalities are related not only to sociological assets-socio-economic status and education-but also to intra-personal resources such as political interest (Bimber 2003; Delli Carpini 2004). However, where civil society benefits from the new technologies for activism, it also should be conditional on existing systems of political communication. The contours of information flows depend on the social contexts of cost structures to which people respond rationally (Prior 2007). The cost structures of information are shaped not only by socio-economic, political, or cultural conditions but also by the media systems that indigenize the patterns of which civil-society groups form a civic-minded public in relations between the news media and their audiences (Hallin and Mancini 2004; Norris 2009). Media systems have such effects in Asia, so much so that the news media serve as social institutions that affect the formation of social norms, relationships, and trust (Igarashi et al. 2008).

In particular, Asian media systems are organized to provide people with different cost structures for political communication as they go through different developmental trajectories. Since a series of liberalization reforms in the 1990s, commercialization and differentiation have begun to emerge to some extent in Asian media systems, but the path of media development also has been contingent on country-specific structural, cultural, and historical conditions (Hallin and Mancini 2012). Thus, some Southeast Asian media systems have suffered from intense partisanship, statism, corporatism, questionable ownership, and the declining profitability of media businesses, despite different 
levels of the continuation of low-level resources (McCargo 2012). This view of Asian media systems suggests that the growing reach of traditional news outlets is instrumental in government efforts to marginalize dissident voices to varying extents. In this context, the development of journalistic institutions produces unfavorable opportunity structures for civil activists to make their voice heard and mobilize ordinary citizens for elite-challenging action (Romano and Bromley 2005).

Furthermore, some Asian democracies have witnessed the enduring power of traditional media institutions even in this new information environment. In South Korea, the legacy of bureaucratic-authoritarian regimes has led people to trust in the news media far more than they trust political or public institutions (Shin and Park 2008). In Malaysia and Taiwan, along with a trend towards liberalization, the news media have begun to reflect an external pluralism to some extent, and to serve as social institutions to which fragmented elites and publics attend (Hughes 2005). Given the Asian context of media systems, the significance of traditional news outlets endures or even outweighs Internet use alone in political mobilization because political participation, especially unconventional forms, is encouraged by those social institutions with which the people have a relationship (Igarashi et al. 2008). Even if the Internet opens up new opportunities for political communication, we should take into account the enduring power of media systems.

\section{WHY ARE NEWSPAPER MARKET STRUCTURES IMPORTANT?}

Different manifestations of media systems point to varying contexts of opportunity structures in which civil activists, as well as general audiences, are embedded when they form public spheres for collective action (Esser et al. 2012). When it comes to how media systems function as a cause of crosscountry variation in political participation, comparative scholarship has emphasized the significance of newspaper-market structures (Norris 2009; Shehata and Strömbäck 2011). Particularly, the development of newspapermarket structures is important insofar as it represents the extent to which traditional media organizations are entrenched in the news market by achieving a wider readership. This measure is an essential dimension of media systems for understanding how the news media work in public communications and what effects they bring about on the political culture (Hallin and Mancini 2004).

In Western democracies, the press fits into theory as an agency in the flow of public information not only between the government and the governed but also 
among citizens (Norris 2000). This theoretical perspective has revealed some the contextual influences of newspaper-market structures on civic and political engagement. For example, given the average newspaper circulation in an average metropolitan news market, cross-national variations were detected in profiles of hard news media users (Shehata and Strömbäck 2011). The differences were related to a newspaper-centric structure of media markets with lower information costs than for a television-centric media culture (Norris 2000). In a newspaper-centric environment, a civic-minded public relies less on their ability and motivation to use the media for political learning than publics in televisioncentric markets. In the latter environment, although political communication involves the general public to a greater extent, it comes with higher costs of information acquisition and processing necessary to form opinions and participate in the political process. Therefore, the capacity of communication acts for political learning diminishes in the context where news products are designed for a wider circulation; instead, an individual's ability and motivation become more important for his or her information-seeking to participate in politics.

The measure of newspaper-market structures allows us to assess the extent to which media systems provide the public with low-cost (or high-cost) publicaffairs information, which in turn generate cross-country variance in political knowledge and involvement (Aalberg and Curran 2012; Esser et al. 2012; Norris 2000; Shehata and Strömbäck 2011). Accordingly, when the press reaches a wide public, the costs of acquiring information become so low that political participation cuts across the gap in opportunities to get involved in politics. Hallin and Mancini (2004) argues that the development of a mass-circulation press market is connected with the dynamics in which people face a low-cost structure for acquiring political information that engages even those who are not well organized for politics. What matters rather is the presence of intrapersonal resources, such as personal political interest, which motivate people to learn information and translate it into action. Furthermore, with unconventional political participation, the dominance of such traditional news outlets as daily newspapers in the media market provides more opportunities for institutional controls over the dissemination of political narratives. Despite the widespread diffusion of the Internet, ordinary citizens still are required to possess a strong motivation to engage in unconventional forms of political participation.

On the other hand, lack of consolidation of mass-circulation newspapers indicates the limited powers of government institutions to structure the "selective flows of information to the general public" (Mughan and Gunther 2000, 4). Indeed, East and Southeast Asia are regions with a path-dependency 
of successful state-driven development that has enabled political systems to still keep a grip on the media. When the structure of a newspaper market is lagging behind in its public reach, Internet use is therefore likely to provide informal grassroots-mobilizing structures of political information. The technological potential is especially made manifest by the mobilization of those who have tuned out from conventional structures of information flows by facilitating their tuning in to politically relevant activities (Howard 2010). In other words, unconventional political participation becomes more afforded due to the reduced cost structures of mobilization in the absence of media-market structures for widely-circulated newspapers.

Based on this line of reasoning, the following hypotheses are posited. First, in East and Southeast Asia, the development of newspaper-market structures enables the mechanism by which media systems shape the opportunity structures for contentious politics. Specifically, when newspapers have a larger circulation, citizens have lower costs of access to political information by institutions but dissident voices are less likely to be heard. This media environment hinders Internet use for unconventional political participation. Figure 1 illustrates the hypothesized cross-level interaction effects that are to be examined.

H1: If newspapers have a larger circulation in the media environment then Internet use will be less associated with unconventional political participation.

Figure 1. Cross-level Interaction Model of Unconventional Political Participation

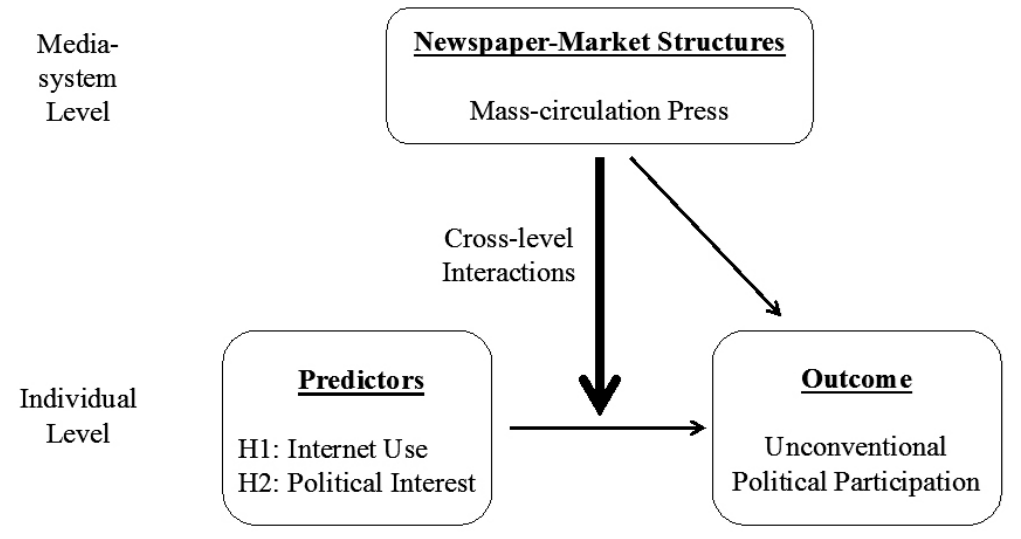


The impact of newspaper-market structures is also related to the importance of intra-personal resources for political participation. In particular, when media systems are structured to increase the barriers to receiving contentious information, mobilization depends more on one's motivations, which can be attributable to strong political interest for learning about politically relevant matters even from alternative information sources and engaging in grassroots organizing around a cause. That is, the development of newspaper-market structures for a mass-circulation press affords low-cost access to information from the media as an institution but, in the meantime, hampers the involvement of general audiences with collective efforts to challenge the status quo. In this situation, individual motivations to engage in politics emerge as key sources of being informed and mobilized for contentious politics (see Figure 1).

H2: If newspapers have a larger circulation in the media environment then unconventional political participation will be more greatly influenced by strong political interest.

\section{DATA}

To test the hypotheses, this study used both individual-level and country-level data on the countries under analysis: two countries in East Asia (South Korea and Taiwan) and six countries in Southeast Asia (Indonesia, Malaysia, The Philippines, Singapore, Thailand, and Vietnam). Using the Asian Barometer Survey (ABS) data sets in Wave 2 (2005-2007) and Wave 3 (2010-2011), individual-level data were pooled across the eight Asian countries in each wave. The ABS was administered by a regional network of research teams who carried out face-to-face interviews with nationally representative samples of voting-age adults (17-19 and above). A standard sample size of the countries ranged from 1,000 to 1,598 respondents and the response rate varied from 24 percent to 90 percent.

Country-level variables came from several data sources to tap Asian media systems in the same years when the ABS produced the individual-level data on each country. The country-level data included indicators of newspaper-market structures such as the total average circulation of daily newspapers, the number of newspaper titles per million habitants, newsprint's share of advertising expenditures in the media market, and the $\mathrm{C}_{4}$ index as the circulation share of 
the top four newspapers in each country. ${ }^{1}$

These variables were obtained from the World Press Trends (WPT) data set published annually by the World Association of Newspapers and News Publishers. The WPT has provided authoritative data on the newspaper industry in more than 70 countries. In doing so, newspapers were operationalized as national dailies because they were considered more relevant to the informational capacity of the media than were local or regional newspapers with a keen interest in maximizing readership (Hallin and Mancini 2004).

Also, the country-level data included socio-economic, democratic, and infrastructural factors that affect the new media environment. These variables included the Human Development Index (HDI), ${ }^{2}$ the Polity score, ${ }^{3}$ the Freedom of the Press Index, ${ }^{4}$ and the diffusion rates of Internet use and mobile cellular phone subscriptions. As reported by the International Telecommunications Union, the national counts of Internet users and the numbers of cellular mobile telephone subscribers were tabulated. To do so, the Technology Distribution Index (TDI) was used, with the technological variables constructed to reflect each country's share of technology adoption in the Asian region weighted against its GDP at PPP relative to the total regional output (Howard et al. 2009). This index captures the impact of political culture on technology diffusion beyond the impact of economic wealth. Also, given the impact of economic wealth on the penetration of newspapers, the circulation of national dailies was derived in line with the TDI by weighting each country's relative share of the total circulation in the Asian region against its relative share of the total regional GDP at PPP. The

${ }^{1}$ The ratio of newspaper circulation to television-viewing has been found to be an important dimension of newspaper-market structures (Norris 2000; Shehata and Strömbäck 2011). However, there was a lack of reliable data on the average daily minutes of total television watched in Asian countries. Therefore, newspaper-centrism was measured by advertising expenditures compared with television. This proxy measure is relevant to estimates of not only their market share (Picard 2008), but also their media-usage patterns (Elvestad and Blekesaune 2008).

2 The HDI, created by the United Nations Development Programme, offered cross-country estimates of socio-economic development based on a combination of annual data about life expectancy, average years of schooling, and gross national income per capita. In 2013, for instance, the HDI ranged from 0.944 for Norway (the highest level of human development) to 0.337 for Niger (the lowest).

3 The Polity score, published by the Polity IV project, provided time-series, cross-national data on comparable qualities of democracy relative to autocracy established in governing institutions (Marshall and Gurr 2014). This score ranked each Asian regime annually between -10 (complete autocracy) and 10 (complete democracy).

4 The Freedom of the Press Index, from the Freedom House, measured the level of legal, political, and economic restrictions placed upon the media in each country annually. The index ranged from zero (least free) to 100 (most free). 
country-level data are summarized in Appendix 1.

\section{OUTCOME VARIABLE}

Serving as the dependent variable in this study, unconventional political participation was conceptualized as citizens' actual involvement in noninstitutionalized direct political action. This outcome variable was operationalized by differentiating between those who had participated in protest activities and those who had never participated. The variable was derived from respondent reports of political action in the past three years, which were available from the ABS data set, such as: 1) getting together with others to raise an issue or sign a petition; 2) attending a demonstration or protest march; and 3) using force or violence for a political cause. Using these items, the dependent variable produced dichotomous results, placing respondents into those who had engaged in some kind of unconventional political act (10.67 percent in Wave 2; 16.51 percent in Wave 3) and those who had not engaged in any unconventional political action.

\section{INDIVIDUAL-LEVEL EXPLANATORY AND CONTROL VARIABLES}

As a key explanatory variable of interest, Internet use was taken into account by distinguishing between people who reported using the technology frequently and those who did not. Thus, asking respondents to indicate their frequency of Internet use, a survey item was employed to generate a dummy binary variable coded " 1 " for those who used the technology at least once a week and "o" for those who did so less frequently or never $(M=.31, S D=.46)$. Another explanatory variable to account for variations in political participation was political interest. This variable was measured by using a survey question asking how respondents would assess their interest in politics $(\mathrm{O}=$ not at all interested, $3=$ very interested). Responses for this item were used to generate a four-point variable $(M=1.44, S D=.93)$.

Several individual-level variables were also controlled for, given the psychological mechanism by which intra-personal resources facilitate political participation beyond political interest. The variables included self-efficacy, news consumption, and political discussion. First, self-efficacy was gauged by using an item that asked respondents to evaluate the following statement: "I think I have the ability to participate in politics" ( $0=$ strongly disagree, $3=$ strongly agree). 
This item yielded a four-point measure $(M=1.26, S D=.79)$. Second, hard news use drew on an item that asked respondents how often they followed news about politics and the government ( $\mathrm{O}=$ practically never, $4=$ every day). Using this item, a five-point measure was produced $(M=2.71, S D=1.37)$. Third, political discussion was tapped via an item that measured the frequency with which individuals discussed political matters in a more intimate social setting, such as when they got together with their family members or friends, a method which is found to be effective in mobilization (Eveland and Hively 2009). Responses for this item, ranging from "never" (scored o) to "frequently" (scored 2), were then recoded to a three-point scale $(M=.73, S D=.62)$.

In fitting the model to the data, differences in the social relationships among individuals was controlled for because of the impact on civic engagement, and even political participation (Putnam 1993; 2000). The size of an individual's network was tapped with an item to measure the number of people that the respondent had contact with in a typical week to chat, talk, or discuss matters face-to-face, on the telephone, via mail, or through the Internet. This item was scored on a five-point scale ranging from "0-4 people" to " 50 or more people" $(M=1.60, S D=1.23)$. Organizational membership was also taken into account using items that indicated whether respondents belonged to any social or civic organizations $(M=.40, S D=.49) .{ }^{5}$ Lastly, the demographic and socio-economic characteristics of respondents were controlled for at the individual level. The variables included sex (50 percent female), age ( $M=42.99$ years, $S D=15.16$ years), education (10-point scale, median category: incomplete secondary/high school), and household income (five-point scale, median category: low level).

\section{MODELING}

To reveal the impact of media systems, an exploratory factor analysis was run to derive latent but meaningful dimensions of the newspaper-market structure from the country-level data. This method was intended to isolate particular newspaper-market structures that were presumed to be associated with media-market development and political influence. The extracted factorscores were used as media-system variables in turn to test their moderating

\footnotetext{
${ }^{5}$ The list of organizations included political parties, residential and community associations, religious groups, sports and recreational clubs, culture organizations, charities, public-interest groups, labor unions, farmer unions or agricultural associations, professional organizations, business associations, parent-teacher associations, consumer cooperatives, alumni associations, and others.
} 
effects on individual-level relationships. The purpose of this analysis was not only to identify the characteristics of Asian media systems but also to create country-level variables that overcame the issue of multicollinearity, as some of the original indicators were highly correlated with one another. The Bartlett method was used to produce unbiased scores for each media system, which were correlated only with their underlying factor. The Bartlett scores were then treated as media-system variables characterizing the newspaper-market structures of the Asia countries under study.

Subsequently, multilevel analyses were conducted to test the cross-level interactions between newspaper-market structures and Internet usage in predicting unconventional political participation. ${ }^{6}$ Using the lme4 package (Bates et al. 2014) in the R environment, a generalized linear mixed-effects model was fitted to the data.? In each multilevel model, an interaction term was included to test whether the relationship between individual-level predictors was dependent on a function of country-level predictors. ${ }^{8}$ It should be noted that there was concern about this multilevel modeling in relation to the small sample size at the country level. The number of the macro-level units used in analysis was 16 (eight countries in two survey years). This issue might lead to biased estimates for the standard errors of the fixed and random parameters at the macro-level with small sample sizes. However, a previous study found that the problem of small macro-level sample sizes was relevant only for inaccurate estimates of the macro-level standard errors (Maas and Hox 2005). Meanwhile, its results rendered unbiased parameter estimates and their standard errors not only for the micro-level effects but also the interaction with macro-level effects. Mathieu et al. (2012) also argued that, in testing cross-level interactions, statistical power was garnered more by the average sample size of the micro-level units than the macro-level sample size. Accordingly, given the purposes of this study, multilevel

${ }^{6}$ Before fitting the multilevel model, an "intercept-only" model was estimated to calculate an intra-class correlation (ICC) beforehand. This procedure estimates the correlation between values of two randomly drawn micro-units in the same randomly-drawn macro-unit. That is to say, ICC assesses the proportion of variance in the outcome variable attributable to cross-country and between-year differences. The computation of ICC yielded that approximately eight percent of the total variation in political participation was attributable to differences across countries and between survey years.

${ }^{7}$ This modeling technique permitted disentangling the variance among the eight countries with two survey years from the within-country variance among individuals (Hox 2010). Doing so enabled explanation of variations between the two survey years and across the eight countries (nested within a survey wave), as well as across individuals (nested within a country in a survey wave).

${ }^{8}$ The random effects of the slopes for the predictors, varying across macro-level units, were not included in the model because they were not of concern in this study. 
modeling was appropriate for estimating not only the main effects of individuallevel explanatory variables but also cross-level interaction effects between individual-level and country-level variables.

\section{RESULTS}

Using the varimax rotation method, the exploratory factor analysis of the country-level variables yielded four factors that accounted for 86 percent of the total variance in the data. Table 1 summarizes the results of this fourfactor solution. ${ }^{9}$ The first factor explains concentration of newspapers most, along with an increase in the HDI and a decrease in TDI for mobile-phone subscriptions. Termed 'market concentration,' this factor reflects the degree of concentration in the newspaper-market structure. The second factor affects the TDI for total average circulation of national paid-for dailies on top of an increase in the TDIs for Internet users. This factor defines 'development of a mass-circulation press' as a key variable of interest. The third factor is labeled 'democratic institutions,' related to the Polity score and the Freedom of the Press index, and reflects the extent to which the media are free from restrictive regulations and government controls. The final factor has a strong effect on the number of national newspaper titles per million inhabitants, but a weak effect on the newspaper share of advertising expenditures. Thus, this factor, dubbed 'market competition,' is considered indicative of the degree to which free-market competition is created in the newspaper industry. These media-system variables were used to fit the multilevel model of unconventional political participation.

Table 1. Loadings for Common Factors of Asian Media Systems

\begin{tabular}{l|c|c|c|c}
\hline & Factor 1 & Factor 12 & Factor 3 & Factor 4 \\
\cline { 2 - 5 } \multicolumn{1}{c}{ Manifest Indicators } & $\begin{array}{c}\text { Market } \\
\text { Concentration }\end{array}$ & $\begin{array}{c}\text { Mass- } \\
\text { circulation } \\
\text { Press }\end{array}$ & $\begin{array}{c}\text { Democratic } \\
\text { Institutions }\end{array}$ & $\begin{array}{c}\text { Market } \\
\text { Competition }\end{array}$ \\
\hline HDI & 0.79 & -0.22 & 0.33 & 0.39 \\
Mobile Phone Distribution & -0.76 & 0.45 & -0.11 & -0.40 \\
C4 Index of Newspaper Market & 0.95 & -0.22 & -0.17 &
\end{tabular}

${ }^{9}$ Given the relatively small sample size of 16 observations, a cut-off at $|0.50|$ was strictly adopted. This means that, in extracting factors from the data, country-level items were retained only if an absolute value of a factor loading was 0.50 or greater. This procedure made interpretation of the factor loadings easier and more meaningful. 


\begin{tabular}{l|l|l|l|l} 
Internet Use Distribution & -0.16 & 0.67 & -0.16 & \\
Newspaper Circulation Index & -0.25 & 0.96 & & \\
Polity Score & -0.12 & -0.25 & 0.88 & 0.12 \\
Press Freedom Index & 0.15 & & 0.97 & 0.10 \\
Newspaper Titles per Million & 0.24 & 0.13 & 0.24 & 0.93 \\
Advertising Expenditures & 0.34 & -0.45 & & 0.50 \\
\hline Eigen Value & 2.41 & 1.96 & 1.95 & 1.45 \\
Explained Variance & 0.27 & 0.22 & 0.22 & 0.16 \\
Cumulative Explained Variance & 0.27 & 0.49 & 0.70 & 0.86 \\
\hline
\end{tabular}

Note: Varimax Rotation, loadings in bold are values above 1.50 .

Source: Author's calculations based on data from the United Nations Development Programme's Human Development Index, ICT Indicators of the International Telecommunication Union, The Polity IV Project's Polity Score, Freedom House's Freedom of the Press Index, and World Association of Newspapers' World Press Trends.

Two cross-level interaction models were fitted to the hierarchical data set in which the individual-level variables were nested within the media-system variables. ${ }^{10}$ The results of the first interaction model are presented in Table 2. Maximum likelihood estimates show that an individual's political participation is related to his or her frequent use of the Internet and higher levels of interest in politics. In particular, Internet use has a robust positive relationship with unconventional political participation, as its coefficient is the largest of all the determinants. Being a frequent Internet user means an 81 percent increase in the odds of unconventional political participation $(\mathrm{p}<0.001)$. In addition, the multilevel model confirms that political action is significantly predicted by political interest: a one-unit increment in this variable is expected to increase the odds of participation by six percent. Not surprisingly, the results also support the impact of personal psychology as a mediator of political action: each oneunit increment in self-efficacy, hard news consumption, and political discussion increases the odds of participation by 18 percent, 20 percent, and 33 percent,

10 Before the analysis, standardization was conducted on each individual-level independent variable by centering it on the country-specific mean and dividing it by its standard deviation in order to ensure comparability across countries. Doing so allowed for placing of those variables on a common scale across countries, as well as within each country. Additionally, survey weighting was taken into consideration for inference in analysis of the cross-national data with unequal sampling probabilities between, as well as within, countries. Insofar as unconventional political action was attributable to situational spillover effects plus meso-level institutions-which were not captured by survey data-sampling weights were necessary not only to correct for bias resulting from over- or under-sampling but also to gain in the precision of estimation. 
respectively. ${ }^{11}$ Moreover, the data corroborate that unconventional political participation is associated with membership in social or civic groups. If people belong to such organizations, they are 59 percent more likely to participate than those who are not involved in any association.

Table 2. Multilevel Regression Model's Prediction of Unconventional Political Participation

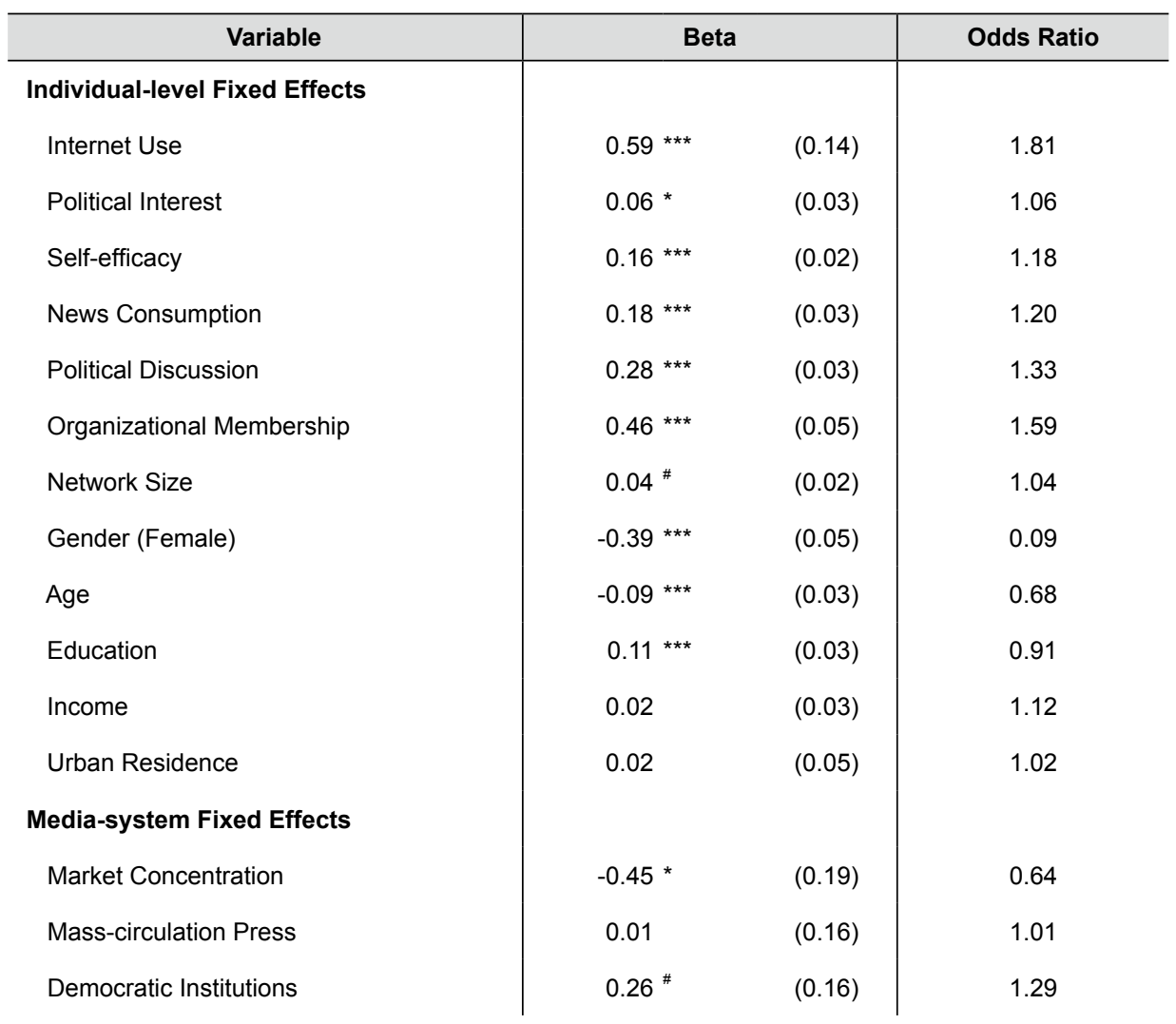

${ }^{11}$ An anonymous reviewer appropriately pointed out that the two variables-political interest and political discussion-involve an endogeneity issue as they are considered unconventional forms of political participation or at least are closely related to the outcome variable. To address the endogeneity problem, a post-hoc analysis was performed to include in the model more conventional forms of political participation, such as attending a campaign meeting. This could act as an instrumental variable related to political interest and political discussion, but presumably not to unconventional political participation. A structural equation modeling, therefore, was run for the sake of the robustness of hypotheses testing, which corroborated the enduring effects of political interest and political discussion, while the instrumental variable was controlled for. For the results of the post-hoc analysis, please contact the author. 


\begin{tabular}{|c|c|c|c|}
\hline Market Competition & 0.10 & $(0.14)$ & 1.11 \\
\hline AlC of Baseline Model & $12,678.64$ & & \\
\hline \multicolumn{4}{|l|}{ Cross-level Interaction Fixed Effects } \\
\hline Internet Use $\times$ Market Concentration & 0.21 & $(0.14)$ & 1.23 \\
\hline Internet Use $\times$ Mass-circulation Press & $-0.25 *$ & $(0.11)$ & 0.78 \\
\hline Internet Use $\times$ Democratic Institutions & 0.07 & $(0.10)$ & 1.07 \\
\hline Internet Use $\times$ Market Competition & -0.09 & $(0.07)$ & 0.92 \\
\hline AlC of Interaction Model & $12,678.61$ & & \\
\hline \multicolumn{4}{|l|}{ Random Effects } \\
\hline Country $\times$ Wave-level $\sigma^{2}$ & 0.24 & & \\
\hline$N$ & 18,230 & & \\
\hline
\end{tabular}

Note: Varimax Rotation, loadings in bold are values above |.50|.

Source: Author's calculations based on data from the United Nations Development Programme's Human Development Index, ICT Indicators of the International Telecommunication Union, The Polity IV Project's Polity Score, Freedom House's Freedom of the Press Index, and World Association of Newspapers' World Press Trends.

Given the media-system variables and their interactions with Internet use, 'market concentration' only predicts participation in unconventional political action directly. If media systems in East and Southeast Asia have more concentrated market structures then the likelihood of participation decreases by 36 percent $(p<0.05)$. As expected, a small sample size of macro-level units hinders precision but yields a relatively large variance of the estimates. However, regarding the interaction estimates, the standard errors diminish to some extent. The multilevel model especially substantiates that the relationship between Internet use and unconventional political participation is contingent on development of a mass-circulation press. When media systems are structured by larger circulations of national dailies, the impact of Internet use on protest action become weaker by 22 percent $(p<0.05)$. The findings corroborate $\mathrm{H} 1$.

The moderating effects of media systems are further examined in the second interaction model. Table 3 presents the results of this multilevel model to examine whether unconventional political participation is differently associated with political interest and Internet use according to development of a masscirculation press. The data show that Internet use retains its decreasing relationship with unconventional political participation in a media environment that has a large circulation of national dailies. Meanwhile, political interest has a greater influence in the media system structured by strong development of 
a mass-circulation press. A one-unit increment in the development of a masscirculation press leads to a 10 percent increase in the positive relationship between political interest and unconventional political participation $(\mathrm{p}<0.001)$, where all individual- and societal-level covariates are controlled. $\mathrm{H} 2$ is therefore supported. The following section discusses the implications of these results.

Table 3. Mass-circulation Press Model's Prediction of Unconventional Political Participation

\begin{tabular}{|c|c|c|c|}
\hline Variable & \multicolumn{2}{|c|}{ Beta } & Odds Ratio \\
\hline AlC of Baseline Model & $12,678.64$ & & \\
\hline \multicolumn{4}{|l|}{ Cross-level Interaction Fixed Effects } \\
\hline Internet Use $\times$ Mass-circulation Press & $-0.11 *$ & $(0.05)$ & 0.89 \\
\hline Political Interest $\times$ Mass-circulation Press & $0.09 * * *$ & $(0.02)$ & 1.10 \\
\hline -AlC of Mass-circulation Press Model & $12,657.70$ & & \\
\hline \multicolumn{4}{|l|}{ Random Effects } \\
\hline Country $\times$ Wave-level $\sigma^{\wedge} 2$ & .22 & & \\
\hline$N$ & 18,230 & & \\
\hline
\end{tabular}

Note: Weighted maximum likelihood estimates of coefficients with standard errors in parentheses.

$\#<.10 ;{ }^{*} p<.05 ;{ }^{* *} p<.01 ;{ }^{* * *} p<.001$.

Source: Author's calculations based on the ABS data, Waves 2 and 3.

\section{CONCLUSION}

In the diverse contexts of contentious politics, the Internet has expanded organizing capacities for civil-society groups to mobilize for collective action. It has indeed become a transnational trend that, with the proliferation of affordable access to digital networks, the Internet has increasingly shaped the cultural and political identity of the young. In that regard, Howard (2010) argues that Internet use plays a crucial role in bringing about new political communication systems in which civil society develops and is mobilized beyond traditional constraints: the diffusion of Internet use opens up the public space for a civil society where people care more about freedom, pluralism, and even democracy. Although digital networks are not sufficient for political participation, its mobilization necessitates the increasingly strategic use of this technology.

In this study, however, it was argued that the impact of Internet use on mobilizing structures needs to be explicated with regard to the context in which media systems affect information costs; in particular, Asian media systems 
with development of a mass-circulation press offer greater constraints on the digitally-mediated flow of contentious information that aims to encourage protest action. That is, the mobilization impact of Internet usage diminishes when the news market is structured by the presence of national dailies having wider circulation with regard to economic wealth. The newspaper-market structure is therefore a dimension of political institutions that maintain the status quo, which is not simply subsumed under the existing framework of media development, concentration, or democratization. The results suggest that media systems generate an important cross-national variation in the opportunity structures for digitally-enabled citizens to be informed and mobilized for social movements.

To be specific, the development of a mass-circulation press is indicative of unfavorable opportunity structures for contentious politics because media systems prioritize information to seek wider audiences and cut across social cleavages. Accordingly, media outlets dampen political and partisan cues; that is, opinionated, mobilizing content is subordinate to depoliticized, catchall content. As a result, the mobilization capacity of digital networks is constrained by high information costs imposed on civil-society voices. This finding echoes the argument that the processes and patterns of political communication are influenced by the way in which traditional media are structured to shape information costs (Esser et al. 2012; Hallin and Mancini 2004; Norris 2009). This study adds to that scholarship, furthermore, by revealing that personal motivations wield a greater influence on the mobilization of protest in a highcost structure of contentious information from civil-society groups. Even if the Internet reduces the costs of grassroots organizing, its capacities are therefore contingent on the political interest of users for them to overcome the barriers to reaching alternative information sources.

On the other hand, when the circulation of national dailies is limited, the barrier to contentious information is relatively low. In other words, where media systems are structured with a low circulation of newspapers, the news market is likely structured to reflect social cleavages (Hallin and Mancini 2004). As a result, public discourse allows more room for pluralistic voices so that opposing political groups are given more venues to reach general audiences and mobilize them. Contentious information is therefore easier to be communicated through the media and amplified through social networks. The news media are also organized to equip their audiences with information to gain more skills, experiences, and incentives to engage in the mobilization of political groups. Digitally-enabled activists benefit from this opportunity structure for mobilization, such that civil-society voices are heard in the absence of catchall 
content from a mass-circulation press.

It is noteworthy that, in East and Southeast Asia, the mobilizing capacity of Internet use for unconventional political participation is not contingent on democratic institutions, which are intuitively expected to reduce information costs. The reason is ascribable to a trade-off between the state and civil society. Assuredly, the Internet will become less effective for citizen mobilization insofar as authoritarian governments have the ability to increase the cost structures of being informed about, and involved in, collective action (Morozov 2011; Pearce and Kendzior 2012). When people see higher costs and greater risks than benefits, there will be greater constraint on participation. Yet, governments are not always successful in suppressing mobilization. Rather, civil-society groups have also shown that the technology enables them to increase the benefits of maintaining communities, as well as reducing the costs of forging new ties and coordinating protest activities (Howard 2010; 2015).

Certainly, interpretation of the results should be undertaken with caution since newspaper-market structures provide only a partial picture of Asian media systems. The relative underdevelopment of professional journalism, as well as persistent state intervention in the media, provide meaningful research questions for a better appraisal of the impact of Internet usage in the context of democratization. Although strong media-party parallelism is regarded as peculiar to the European Polarized Pluralist Model (Hallin and Mancini 2004; Van Kempen 2007), media partisanship is often observed in many Asian countries as well. Also, Asian media systems may lack institutional influence on the emergence of digitally-mediated dissent. For example, clientelism in the region has often prevailed over internal pluralism and autonomy for news organizations, which are then exploited in political struggles among government factions (McCargo 2003). In this regard, McCargo (2012, 216) argues that Asian media systems offer another dimension to consider insofar as "journalists are often engaged in relatively mechanical news-gathering activities that serve the interests of the adjacent power holder".

Also, in some Southeast Asian countries, socio-political instability and prevalent corruption have also undermined the press as a trustworthy source of information. According to Huntington's (1996) indigenization thesis, East Asia has the cultural legacy of Confucianism that prioritizes harmony over confrontation and deference to authority over personal liberty, so media systems are bound up with the political world. Moreover, since many Asian countries share a history of colonialism and post-colonial authoritarianism, media development has occurred in isolation from the growth of civil-society groups or mass political parties because of strong state intervention and proactive 
subsidies. Given the nascent nature of the democratic experiment in these countries, some scholars may argue that Asian media systems are not relevant to the power of institutions in politics. The limitations of this study should be taken into careful consideration in any future research on the existing media systems in Asia and their effects on change in democratic cultures.

Notwithstanding the skepticism about media systems, this study shows that newspaper-market structures do have an impact on unconventional political participation because of their capacity to shape the information costs for dissident voices to be heard and grassroots organizing to take place. In East and Southeast Asia, getting together to raise an issue, signing a petition, or attending a demonstration are forms of unconventional political action that have been marginalized by traditional systems of political communication or restricted to small civil-society groups or college-student associations (Castells 2008). Internet diffusion, however, has changed the dynamics of public discourses. Although many people may lack resources and opportunities to be informed in a traditional setting, they now are given a new means of engagement in unconventional political action because they are Internet users. However, this causal mechanism is differentiated into Asian media systems that have an influence on the opportunity structures of aggregate-level political learning and involvement. In this sense, media systems are institutions that have an influence on political change that is not subservient to such system-level conditions of political participation. The media situation is important for Internet use to influence the opportunity structures of mass mobilization in the contexts of social-movements.

\section{REFERENCES}

Aalberg, Toril, and James Curran. 2012. How Media Inform Democracy: A Comparative Approach. New York, NY: Routledge.

Abbott, Jason. 2012. "Democracy@internet.Org Revisited: Analyzing the Socio-Political Impact of the Internet and New Social Media in East Asia." Third World Quarterly 33(2), 333-357.

Ayres, Jeffrey M. 1999. "From the Streets to the Internet: The Cyber-Diffusion of Contention." The Annals of the American Academy of Political and Social Science 566(1), 132-143.

Barnes, Samuel H., and Max Kaase. 1979. Political Action: Mass Participation in Five Western Democracies. Beverly Hills, CA: Sage Publications.

Bates, Douglas, Martin Mächler, Ben Bolker, and Steve Walker. 2014. 
"Fitting Linear Mixed-Effects Models Using Lme4." ArXiv Preprint ArXiv:1406.5823.

Bennett, W. Lance, and Alexandra Segerberg. 2013. The Logic of Connective Action: Digital Media and the Personalization of Contentious Politics. New York, NY: Cambridge University Press.

Bimber, Bruce A. 2003. Information and American Democracy: Technology in the Evolution of Political Power. New York, NY: Cambridge University Press.

Castells, Manuel. 2008. "The New Public Sphere: Global Civil Society, Communication Networks, and Global Governance." The Annals of the American Academy of Political and Social Science 616(1), 78-93.

. 2012. Networks of Outrage and Hope: Social Movements in the Internet Age. Malden, MA: Polity.

Curran, James, Shanto Iyengar, Anker Brink Lund, and Inka SalovaaraMoring. 2009. "Media System, Public Knowledge and Democracy: A Comparative Study." European Journal of Communication 24(1), 5-26.

Dahl, Robert A. 1998. On Democracy. New Haven, CT: Yale University Press.

Deibert, Ronald, John Palfrey, Rafal Rohozinski, and Jonathan Zittrain eds. 2012. Access Contested: Security, Identity, and Resistance in Asian Cyberspace Information Revolution and Global Politics. Cambridge, MA: MIT Press.

Delli Carpini, Michael X. 2004. "Mediating Democratic Engagement: The Impact of Communications on Citizens' Involvement in Political and Civic Life." In Lynda Lee Kaid ed., Handbook of Political Communication Research. Mahwah, NJ: Lawrence Erlbaum Associates, 357-394.

DiMaggio, P. E. Hargittai, W. R. Neuman, and J. P. Robinson. 2001. "Social Implications of the Internet." Annual Review of Sociology 27, 307-336.

Downs, Anthony. 1957. An Economic Theory of Democracy. New York, NY: Harper.

Elvestad, Eiri, and Arild Blekesaune. 2008. "Newspaper Readers in Europe: A Multilevel Study of Individual and National Differences." European Journal of Communication 23(4), 425-447.

Esser, Frank, Claes H de Vreese, Jesper Strömbäck, Peter van Aelst, Toril Aalberg, James Stanyer, Günther Lengauer, Rosa Berganza, Guido Legnante, and Stylianos Papathanassopoulos. 2012. "Political Information Opportunities in Europe: A Longitudinal and Comparative Study of Thirteen Television Systems." The International Journal of Press/Politics 17(3), 247-274. 
Eveland, William P, and Myiah Hutchens Hively. 2009. "Political Discussion Frequency, Network Size, and 'Heterogeneity' of Discussion as Predictors of Political Knowledge and Participation." Journal of Communication 59(2), 205-224.

George, Cherian. 2006. Contentious Journalism and the Internet: Toward Democratic Discourse in Malaysia and Singapore. Seattle, WA: University of Washington Press.

Habermas, Jürgen. 2006. "Political Communication in Media Society: Does Democracy Still Enjoy an Epistemic Dimension? The Impact of Normative Theory on Empirical Research." Communication Theory 16(4), 411-426.

Hallin, Daniel C., and Paolo Mancini. 2004. Comparing Media Systems: Three Models of Media and Politics. New York, NY: Cambridge University Press.

Howard, P. N. 2015. Pax Technica: How the Internet of Things May Set Us Free or Lock Us Up. New Haven, CT: Yale University Press.

Howard, Philip N. 2010. The Digital Origins of Dictatorship and Democracy: Information Technology and Political Islam. New York, NY: Oxford University Press.

Howard, Philip N., Ken Anderson, Laura Busch, and Dawn Nafus. 2009. "Sizing up Information Societies: Toward a Better Metric for the Cultures of ICT Adoption." The Information Society 25(3), 208-219.

Hox, J. J. 2010. Multilevel Analysis Techniques and Applications. New York, NY: Routledge.

Hughes, Caroline. 2005. "Introduction: Democratization and Communication in the Asia-Pacific Region." Pacific Affairs 78(1), 9-22.

Huntington, Samuel P. 1996. The Clash of Civilizations and the Remaking of World Order. New York, NY: Simon \& Schuster.

Igarashi, Tasuku, Yoshihisa Kashima, Emiko S Kashima, Tomas Farsides, Uichol Kim, Fritz Strack, Lioba Werth, and Masaki Yuki. 2008. "Culture, Trust, and Social Networks." Asian Journal of Social Psychology 11(1), 88-101.

Inglehart, Ronald, and Christian Welzel. 2009. "How Development Leads to Democracy: What We Know about Modernization." Foreign Affairs 88(2), 33-48.

Maas, Cora J. M., and Joop J. Hox. 2005. "Sufficient Sample Sizes for Multilevel Modeling." Methodology 1(3), 85-91.

Marshall, Monty G., and Ted Robert Gurr. 2014. "Polity IV Project: Political Regime Characteristics and Transitions, 1800-2013." Accessed at 
http://www.systemicpeace.org/polity/polity4.htm (March 21, 2014).

Mathieu, John E., Herman Aguinis, Steven A. Culpepper, and Gilad Chen. 2012. "Understanding and Estimating the Power to Detect CrossLevel Interaction Effects in Multilevel Modeling." Journal of Applied Psychology 97(5), 951-966.

McAdam, Doug, Sidney Tarrow, and Charles Tilly. 2009. "Comparative Perspectives on Contentious Politics." In M. I. Lichbach and A. S. Zuckerman eds., Comparative Politics: Rationality, Culture, and Structure. New York, NY: Cambridge University Press, 260-290.

McCargo, Duncan. 2003. Media and Politics in Pacific Asia. New York, NY: Routledge Curzon.

. 2012. "Partisan Polyvalence: Characterizing the Political Role of Asian Media." In Daniel C. Hallin and Paolo Mancini eds., Comparing Media Systems Beyond the Western World. New York, NY: Cambridge University Press, 201-223.

Morozov, Evgeny. 2011. The Net Delusion: The Dark Side of Internet Freedom. New York, NY: PublicAffairs.

Mughan, Anthony, and Richard Gunther. 200o. "The Media in Democratic and Nondemocratic Regimes: A Multilevel Perspective." In Richard Gunther and Anthony Mughan eds., Democracy and the Media: A Comparative Perspective. New York, NY: Cambridge University Press, $1-27$.

Norris, Pippa. 2000. A Virtuous Circle: Political Communications in Postindustrial Societies. New York, NY: Cambridge University Press.

. 2002. Democratic Phoenix: Reinventing Political Activism. New York, NY: Cambridge University Press.

. 2009. "Comparative Political Communications: Common Frameworks or Babelian Confusion?” Government \& Opposition 44(3), 321-340.

Paek, Hye-Jin, So-Hyang Yoon, and Dhavan V. Shah. 2005. "Local News, Social Integration, and Community Participation: Hierarchical Linear Modeling of Contextual and Cross-Level Effects.” Journalism \& Mass Communication Quarterly 82(3), 587-606.

Pearce, Katy E., and Sarah Kendzior. 2012. "Networked Authoritarianism and Social Media in Azerbaijan." Journal of Communication 62(2), 283298.

Picard, Robert G. 2008. "Shifts in Newspaper Advertising Expenditures and Their Implications for the Future of Newspapers." Journalism Studies 9(5), 704-716.

Prior, Markus. 2007. Post-Broadcast Democracy: How Media Choice Increases 
Inequality in Political Involvement and Polarizes Elections. New York, NY: Cambridge University Press.

Putnam, Robert D. 1993. Making Democracy Work: Civic Traditions in Modern Italy. Princeton, NJ: Princeton University Press. . 2000. Bowling Alone: The Collapse and Revival of American Community. New York, NY: Simon \& Schuster.

Romano, Angela Rose, and Michael Bromley eds. 2005. Journalism and Democracy in Asia. New York, NY: Routledge.

Shehata, Adam, and Jesper Strömbäck. 2011. "A Matter of Context: A Comparative Study of Media Environments and News Consumption Gaps in Europe." Political Communication 28(1), 110-134.

Shin, Doh Chull, and C. M. Park. 2008. "The Mass Public and Democratic Politics in South Korea: Exploring the Subjective World of Democratization in Flux." In Yunhan Zhu ed., How East Asians View Democracy. New York, NY: Columbia University Press, 39-60.

Shirky, Clay. 2011. "Political Power of Social Media." Foreign Affairs 9o(1), 28-41.

Stockemer, Daniel. 2014. "What Drives Unconventional Political Participation? A Two Level Study." The Social Science Journal 51(2), 201-211.

Van Kempen, Hetty. 2007. "Media-Party Parallelism and Its Effects: A CrossNational Comparative Study." Political Communication 24(3), 303320.

Van Laer, Jeroen. 2010. "Activists Online and Offline: The Internet as an Information Channel for Protest Demonstrations." Mobilization: An International Quarterly 15(3), 347-366.

Verba, Sidney, Norman H. Nie, and Jae-on Kim. 1978. Participation and Political Equality: A Seven-Nation Comparison. New York, NY: Cambridge University Press.

Verba, Sidney, Kay Lehman Schlozman, and Henry E Brady. 1995. Voice and Equality: Civic Voluntarism in American Politics, Vol. 4. Cambridge, MA: Harvard University Press.

Xenos, Michael, and Patricia Moy. 2007. "Direct and Differential Effects of the Internet on Political and Civic Engagement." Journal of Communication 57(4), 704-718. 
Appendix 1. Raw Data on Country-Level Manifest Indicators of Media Systems

\begin{tabular}{ccccccccccc}
\hline Country & Year & HDI & Polity & Press & Internet & Mobile & Circulation & Ad & Title & C4 \\
\hline \multirow{2}{*}{ Indonesia } & 2006 & .640 & 8 & 46 & 10,850 & 63,803 & 4900 & .50 & 1.46 & 26.28 \\
& 2011 & .678 & 8 & 51 & 29,939 & 249,806 & 9255 & .69 & 2.46 & 21.41 \\
\hline \multirow{2}{*}{ Philippines } & 2005 & .638 & 8 & 60 & 4,632 & 34,779 & 3780 & .25 & .31 & 19.34 \\
& 2010 & .651 & 8 & 54 & 23,361 & 83,150 & 3800 & .20 & .29 & 33.71 \\
\hline \multirow{2}{*}{ South Korea } & 2006 & .856 & 8 & 70 & 37,779 & 40,197 & 13274 & 1.23 & 3.80 & 55.31 \\
& 2011 & .886 & 8 & 68 & 41,715 & 52,507 & 12505 & .82 & 7.07 & 41.98 \\
\hline \multirow{2}{*}{ Taiwan } & 2006 & .854 & 10 & 80 & 14,670 & 23,249 & 4200 & .75 & 1.09 & 57.10 \\
& 2010 & .879 & 10 & 75 & 16,426 & 27,840 & 3350 & .49 & .91 & 58.06 \\
\hline \multirow{2}{*}{ Thailand } & 2006 & .685 & -5 & 41 & 11,306 & 40,125 & 7300 & .36 & .68 & 48.63 \\
& 2010 & .715 & 4 & 38 & 14,874 & 71,726 & 7525 & .33 & .68 & 47.18 \\
\hline \multirow{2}{*}{ Vietnam } & 2005 & .598 & -7 & 23 & 14,375 & 18,892 & 3700 & .23 & .66 & 33.24 \\
& 2010 & .629 & -7 & 17 & 26,644 & 111,570 & 4000 & .14 & .63 & 35.75 \\
\hline \multirow{2}{*}{ Singapore } & 2007 & .747 & 3 & 35 & 14,935 & 23,347 & 2750 & 1.73 & 1.04 & 40.33 \\
& 2010 & .894 & -2 & 32 & 3,604 & 7,385 & 964 & 1.23 & 1.58 & 79.13 \\
\hline & 2011 & .768 & 6 & 37 & 17,543 & 36,661 & 2596 & 1.42 & 1.08 & 51.63 \\
\hline
\end{tabular}

Note: $\mathrm{HDI}=$ Human Development Index; Polity = Polity score; Press = Press Freedom Index; Internet = Number of Internet users ('000); Mobile = Number of Mobile Cellular Subscriptions ('000); Circulation = National Paid-for Dailies' Total Average Circulation; $\mathrm{Ad}=$ Advertising Expenditures on Newspapers in proportion to Television; Title $=$ Number of National Paid-for Dailies' Titles per Million Inhabitants; C4 = C4 Index of Newspaper Market in Circulation.

Source: The Polity IV Project; Freedom House; United Nations Development Programme; and author's calculations of newspaper market indicators based on data from World Association of Newspapers' World Press Trends. 


\section{Appendix 2. Survey Questions}

\section{Unconventional Political Action}

Here is a list of actions that people sometimes take as citizens. For each of these, please tell me whether you, personally, have never, once, or more than once done any of these things during the past three years.

a. Got together with others to raise an issue or sign a petition

o. Never Done

1. Once

2. More than once

b. Attended a demonstration or protest march

o. Never Done

1. Once

2. More than once

b. Used force or violence for a political cause

o. Never Done

1. Once

2. More than once

\section{Network Size}

On average, about how many people do you have contact with in a typical week day?

o. 0 -4 people

1. 5-9 people

2. 10-19 people

3. 20-49 people

4. 50 or more people

\section{Organizational Membership}

Are you a member of any organizations or formal groups?

o. No

1. Yes 


\section{Political Interest}

How interested would you say you are in politics?

o. Not at all interested

1. Not very interested

2. Somewhat interested

3. Very interested

\section{Self-efficacy}

I think I have the ability to participate in politics.

o. Strongly disagree

1. Somewhat disagree

2. Somewhat agree

3. Strongly agree

\section{News Consumption}

How often do you follow news about politics and government?

o. Practically never

1. Not even once a week

2. Once or twice a week

3. Several times a week

4. Every day

\section{Political Discussion}

When you get together with your family members or friends, how often do you discuss political matters?
o. Never
1. Occasionally
2. Frequently

\section{Internet Use}

How often do you use the Internet?

0 . Never

1. Hardly ever

2. Several times a year

3. At least once a month

4. At least once a week

5. Almost daily 
